\title{
Design and Implementation of Ubiquitous Health System (U-Health) using Smart-Watches Sensors
}

\author{
V. Razavi termeh ${ }^{\text {a, }}$, A. Sadeghi Niaraki ${ }^{\text {a }}$, \\ ${ }^{a}$ GIS Dept., Geoinformation Technology Center of Excellence, Faculty of Geodesy\&Geomatics Eng, \\ K.N.Toosi Univ. of Tech., Tehran, Iran. \\ -vrazavi70@gmail.com - a.sadeghi@kntu.ac.ir
}

Keywords: Ubiquitous Health, Smartphone, Smart-Watch Sensors, GIS

\begin{abstract}
:
Today as diseases grow rapidly, the responsibilities of the health clinics in giving services to patients increase and patients have to be more monitored and controlled. Remote systems of monitoring patients result in reducing cost, ease of movement, and also persistent control of patients by their doctors, so that patient can be monitored without need to go to the clinic.

Recent advances in the field of ubiquitous sciences as well as using smartphones have resulted in increasingly use of this devices in remote monitoring of patients.

The aim of this paper is to design and implement a ubiquitous health system using smartphones and sensors of smart-watches. This is accomplished through the information sent to the smartphone from the sensors of the watch, e.g. heart beat measurement sensor and ultraviolet ray. Then, this information is analyzed in the smartphone and some information based on the position of the patient and the path of him/her using GIS analyses as well as the information about the health level of the patient is sent to the doctor via SMS or phone call. Unnatural heart beats can be resulted in diseases such as Heart Failure and Arterial Fibrillation. With the approach adopted in this study, the patient or the doctor could be aware of these diseases at any time. The proposed approach is a low cost, without need to complex and resilient equipment, system in ubiquitous health that does not limit the movement of the patient.
\end{abstract}

\section{Introduction}

The increasing number of patients needs long-term cares, but these have many costs. In fact, all of the patients need not to be cared by and hospitalized in medical centers in long terms, but some of them can be taken away from medical centers and be allowed to live in their home, while their health conditions is being watched remotely. With regard to the ease of use of smartphones in every place, the patients and their caregivers have showed great interest in remote monitoring. (S. Jassal 1998)

Most of the remote monitoring systems for patients are static and limit the patient's movement. Remote monitoring systems via smartphones have overcame this restriction.

With regard to recent advances in mobile phone technologies and increase in capabilities of these devices, mobile phones are becoming an interface in ubiquitous computing which is beyond the traditional phone services.

Using mobile phones has many reasons, such as capabilities in Location-Based Services (LBS), access to real-time data via Bluetooth, Wi-Fi, GPS, and accelerometer sensor, private information privacy issues, and cost. Furthermore, ubiquitous computing allows access to data in every location, every time, and for every user such that patient's movement has no effect in gathering health relevant information. (K.Elgazzar2012)
In this system, smartphone is not only for monitoring the patient's conditions, but it is used as an interactive interface for patients to communicate with caregivers and physician.

This system can be useful for a wide range of patients. For instance, reminding patients with Alzheimer's disease who may forget their spatial location, reminding individuals under treatment with their time of taking pills, and monitoring on children who need more care. One great advantage of the system is for patients who need permanent care. In addition, the system can be used in inaccessible locations or in critical conditions.

In this paper, we discuss the low-cost and efficient capabilities of smartphones for remote monitoring of patients. Hence, we address the communications between smartphone and smart-watch sensors and information analyses relevant to location and health condition of patient in form of a mobile application. The next section of this paper reviews the related works in this area of research. Then, the architecture of the system is presented. Finally, we conclude about the system.

\section{Related Works}

Recently, institutes of health have shown special insights into the advances in information and communication technologies, especially ubiquitous health to provide electronic health services. Researches in the area of remote 
monitoring on health, in last years, can be categorized in to three main parts: information gathering methods, methods of communication with data, and data processing methods. In this paper, we discuss the role of smartphone devices and related technologies in this area of research.

Kulkarni has developed a health system in mobile environment that was necessary with respect to needs of patient. The role of mobile device in this system was limited to a database for storing user's information.( P. Kulkarni 2011)

Dantas et al. have designed a remote monitoring system using mobile phone in which vital signs is gathered through sensors equipped in the body of patient and the communication method is through ZigBee. Then, the mobile phone sends gathered information to a server in order to storing and further processing and analyses.( S. Da gtas 2008)

Oleshchuk and Fensli have presented new capabilities in remote monitoring systems in a framework form via $5 \mathrm{G}$ networks. They stated that $5 \mathrm{G}$ communications will improve the infrastructures of health systems, such as security development and high bandwidth in the future. Their research mentions the restrictions of current health systems and how to overcome them using $5 \mathrm{G}$ communications.( V. Oleshchuk 2011)

Agarwal et al. have presented a simple conceptual architecture in order to monitoring patients remotely. This architecture consists of a patient's phone device and a database in which the patient's information is stored. The online connection between these is constructed via a web service. In this architecture, medical information is sent to the database via the sensors located in the patient's body or manually by patients.( P. Pawar 2009)

The above systems lack integration mechanisms and collaboration capabilities. The main difference of those systems with ours is that there is no sensor embedded in the body of the patient. In fact, it makes use of sensors that exist in the smart-watches. These watches, among other routine tasks such as showing time, can be used in ubiquitous health systems.

\section{System Architecture}

The advent of smartphones and making use of various sensors, and also development of ubiquitous health systems have enabled these systems for any user at every location. Table 1 indicates some of sensors and capabilities of smartphones applicable in ubiquitous health.( J. Kee-Yin Ng 2011)

Figure 1 shows a general view of the remote system of patient monitoring. In this system, data about heart rate and ultra-violet beams are measured by sensors embedded in the smart-watch and sent to the smartphone. The mechanism of this system is such that the transmission of information between smartphone and sensors embedded in smart-watch at any location and in any time and situation is possible.

Table 1. Features and capabilities of smartphone

\begin{tabular}{|c|c|}
\hline $\begin{array}{l}\text { Component or } \\
\text { module }\end{array}$ & Remarks \\
\hline Phone & $\begin{array}{c}\text { Voice } \\
\text { Communications, } \\
\text { SMS, MMS, } \\
\text { Fax, capturing of } \\
\text { caller ID }\end{array}$ \\
\hline Camera & Image capturing \\
\hline $\begin{array}{l}\text { Video Call } \\
\text { Camera }\end{array}$ & $\begin{array}{l}\text { Capturing user's } \\
\text { own image and } \\
\text { facilitating video } \\
\text { conferencing. }\end{array}$ \\
\hline $\begin{array}{c}\text { Video Display } \\
\& \\
\text { Speaker }\end{array}$ & $\begin{array}{c}\text { Video playback } \\
\text { and display screen } \\
\text { as } \\
\text { lighting panel }\end{array}$ \\
\hline $\begin{array}{l}\text { Microphone\& } \\
\text { Speaker }\end{array}$ & $\begin{array}{l}\text { Audio playback \& } \\
\text { recording }\end{array}$ \\
\hline Flash Light & $\begin{array}{c}\text { Controllable light } \\
\text { source }\end{array}$ \\
\hline $\begin{array}{c}\text { UMTS - } \\
\text { WCDMA }\end{array}$ & $\begin{array}{l}\text { 3G \& 4G (LTE) } \\
\text { communications, } \\
\text { mobile positioning }\end{array}$ \\
\hline WLAN - WiFi & $\begin{array}{c}\text { Wireless LAN } \\
\text { communications, } \\
\text { Wi-Fi } \\
\text { positioning }\end{array}$ \\
\hline GPS & $\begin{array}{c}\text { Positioning: } \\
\text { latitude, longitude, } \\
\text { altitude }\end{array}$ \\
\hline $\begin{array}{l}\text { PAN - } \\
\text { Bluetooth }\end{array}$ & $\begin{array}{c}\text { Personal Area } \\
\text { Network } \\
\text { communications, } \\
\text { positioning, } \\
\text { wireless } \\
\text { connection among } \\
\text { Bluetooth devices }\end{array}$ \\
\hline Gyroscope & $\begin{array}{c}\text { User's orientation } \\
\text { in 3D }\end{array}$ \\
\hline Accelerometer & $\begin{array}{l}\text { User's heading } \\
\text { direction in 3D }\end{array}$ \\
\hline Magnetometer & $\begin{array}{c}\text { Electronic } \\
\text { compass }\end{array}$ \\
\hline $\begin{array}{c}\text { Multi-touch } \\
\text { Panel }\end{array}$ & $\begin{array}{l}\text { Human-Computer } \\
\text { Interaction, } \\
\text { tracking } \\
3 \text { or more points } \\
\text { on the panel }\end{array}$ \\
\hline Data Storage & $\begin{array}{c}\text { Internal/External } \\
\text { storage amount to } \\
\text { GByte }\end{array}$ \\
\hline $\begin{array}{c}\text { Cloud } \\
\text { Computing }\end{array}$ & $\begin{array}{c}\text { Usually for } \\
\text { external storage } \\
\text { and } \\
\text { accessibility }\end{array}$ \\
\hline
\end{tabular}


This system is designed such that the patient himself or herself has access to the information, in addition to the caregivers and physicians.

The remote system of health monitoring consists of two main parts: 1. gathering required parameters, and 2 . transferring the information resulted from parameters to the caregiver or physician. The first step is accomplished automatically via the connection between smart-watches' sensors and the smartphones. The second step is accomplished using a programming interface for smartphone and sending information to the device.

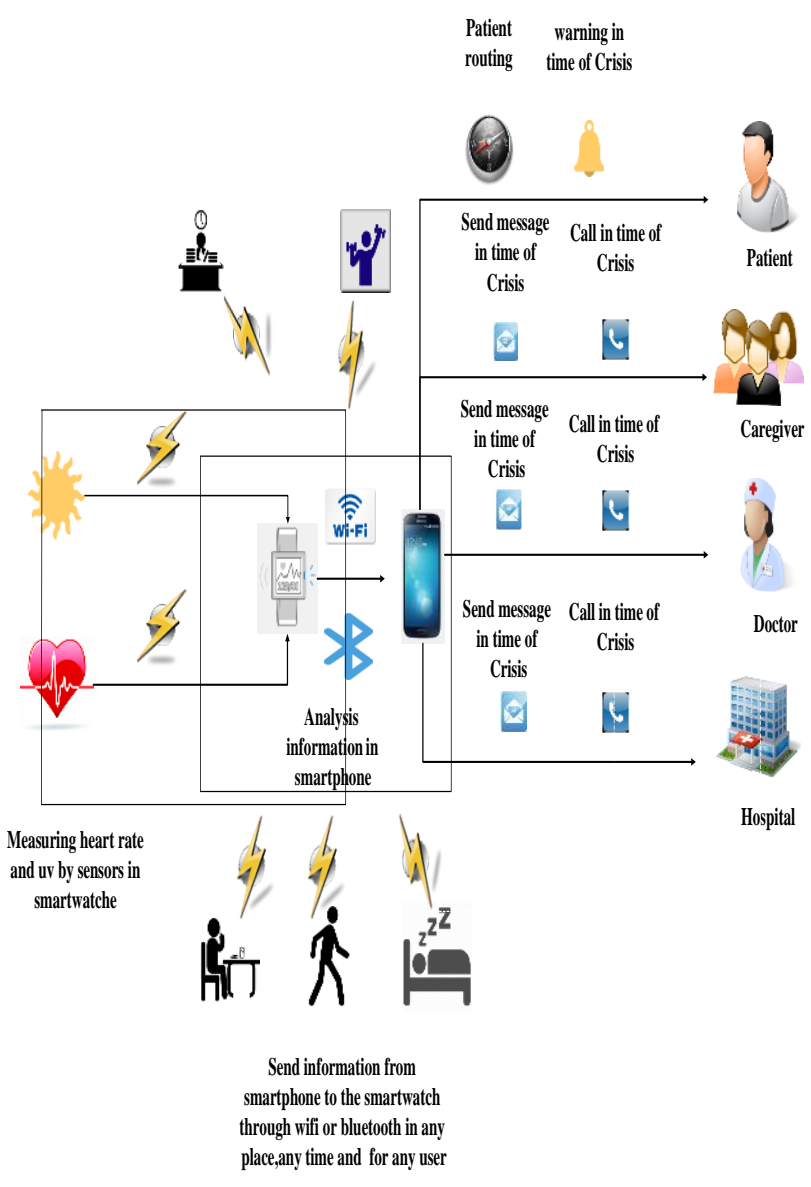

Figure 1. System Architecture
This system communicates in two forms: active and reactive. In active form, data from sensors are sent to the mobile phone continuously. Then a report from these data is prepared for patient and physician. In reactive form, if the information sent to the mobile phone device is in a critical point of hearth rate and UV beams, the system sends a message or calls the patient and the caregivers.

The natural heart rate for various age groups is different. Table 2 shows the natural heart rate.

Table 2. The normal heart rate

\begin{tabular}{|l|c|}
\hline \multicolumn{1}{|c|}{ age groups } & natural heart rate per minute \\
\hline newborns & $100-170$ \\
\hline children aging 1-10 & $60-140$ \\
\hline $\begin{array}{l}\text { children aging 10 and } \\
\text { above and adult men }\end{array}$ & $60-100$ \\
\hline professional sportsmen & $40-60$ \\
\hline aged individuals & $50-65$ \\
\hline adult women & $76-86$ \\
\hline
\end{tabular}

The heart beats higher or lower than the natural limit can be resulted in various heart diseases that have been shown in Table 3.

Table 3. Diseases related to the heart rate

\begin{tabular}{|l|l|}
\hline signs & disease \\
\hline Stroke & Atrial Fibrillation \\
\hline Heart Beats & $\begin{array}{l}\text { Premature Atrial } \\
\text { Contracture/ PAC }\end{array}$ \\
\hline Vertigo - Seizure & Heart Block \\
\hline Vertigo - Fainting & Heart Beats \\
\hline Irregular heart beats & $\begin{array}{l}\text { Paroxysmal tachycardia } \\
(P S V T)\end{array}$ \\
\hline Coagulation - Stroke & Atrial flutter \\
\hline
\end{tabular}

Figure 2 indicates the general algorithm of remote system of health monitoring. Also is indicated other analyses and processing executed in the system. As it can be seen from the figure, after receiving the information and processing on these information, the system initially determines the type of user, according to existing differences in the heart rate of men, women or children. Then, with attention to the heart rate of the user sends messages to or calls the patient or caregiver or physician and informs them of these information. Heart rates higher than the normal can be resulted in heart failure or syncope and heart rates lower than the normal can be resulted in vertigo feelings and fainting. Using Geospatial Information Systems (GISs) and Global Positioning System (GPS), the location of patient can be determined on the map. In emergency situations geospatial information of the patient can be sent to the medical centers. Further, using accelerometer sensors embedded in 
smartphones, the user can be alarmed to change his or her path.

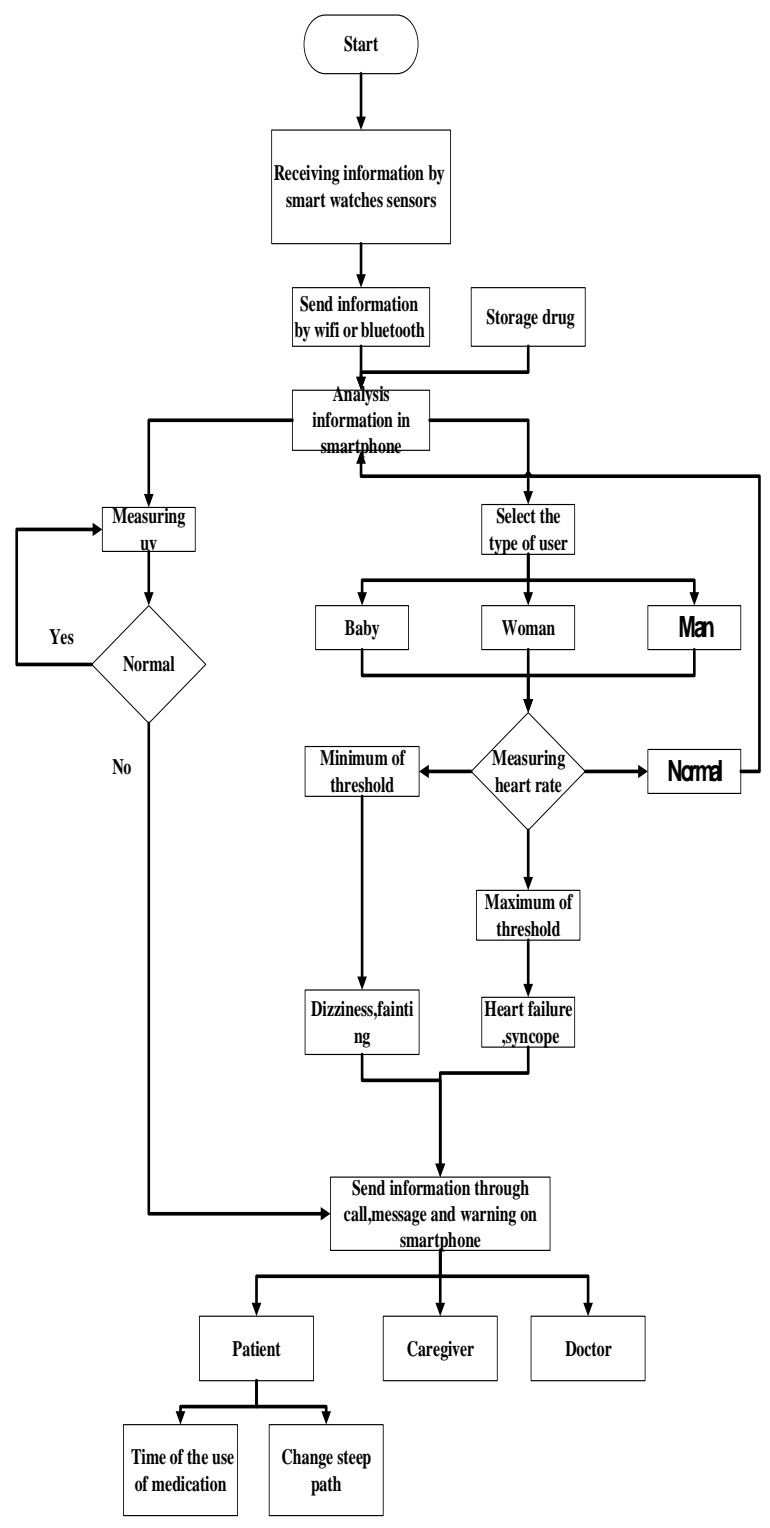

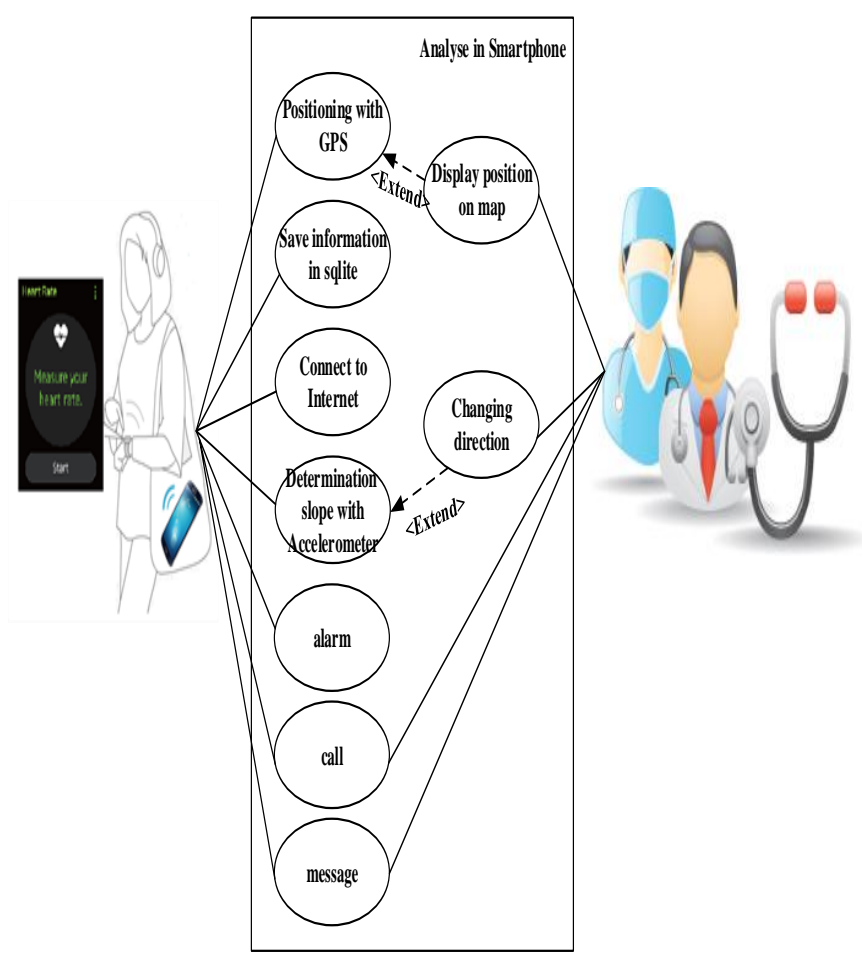

Figure 3. use case diagram

Figure 4 indicates the class diagram of the designed system in which the main components of the system such as smartphone, smart-watch, patient, physician, and functions and sensors used in it have been considered.

Figure 2. general algorithm of remote system of health monitoring

Figure 3 indicates the analyses conducted between the patient and his physician in smartphone in a use case diagram. 


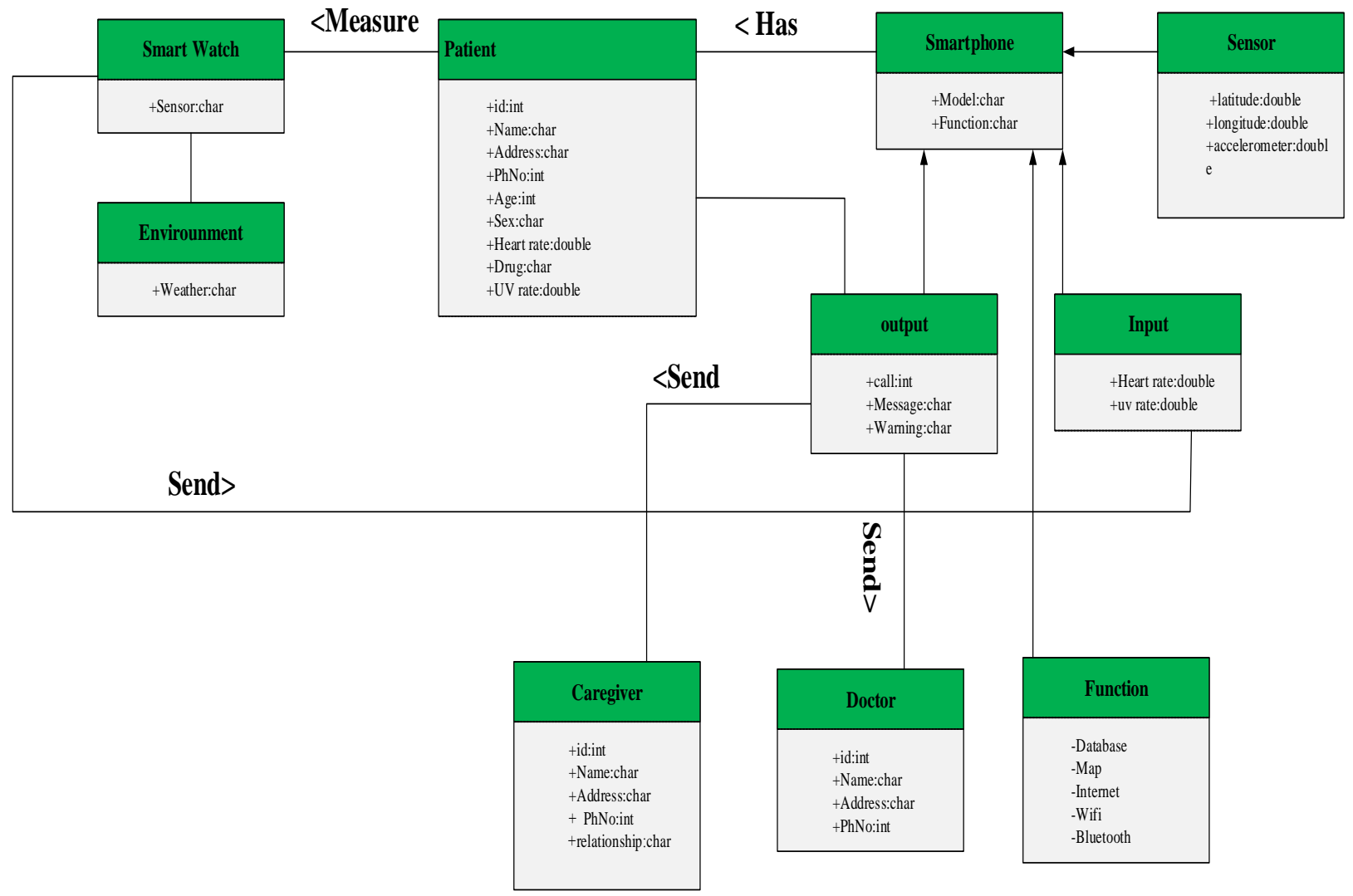

Figure 4. class diagram of the designed system

\section{Conclusions}

In this paper, we designed a ubiquitous health system that sends heart rate signs and UV beams to the smartphone in real-time. Then some analyses applies on these information in the smartphone. After that, the patient, his or her physician or caregiver is informed about the health condition of the patient. In this system, the patient has no restriction for movements. Additionally, this system can be used everywhere at any time and for every user. One of the disadvantages of this system is that the patient has to have the watch on his or her wrist. One of the recommendations for future works is the use of Samsung gera 2 smart-watch or its emulator for sending the information of heart rate and UV beams via Bluetooth to an application in a smartphone and applying analyses in the smartphone. Furthermore, with recent advances in navigation systems in indoor and outdoor applications, patient's route finding in both indoor and outdoor environments is possible.

\section{References}

S. Jassal, J. Brissenden, A. Raisbeck, J. Roscoe, Comparative cost-analysis of two different chronic care facilities for end-stage renal disease patients, Geriatric Nephrology and Urology 8 (1998) 69-76.

K.Elgazzar, M.Aboelfotoh, Patrick Martin, Hossam S. Hassanein , Ubiquitous Health Monitoring Using Mobile Web Services, The 3rd International Conference on Ambient Systems, Networks and Technologies (ANT), Procedia Computer Science 10 ( 2012 ) $332-339$.

P. Kulkarni, Y. Ozturk, mphasis: Mobile patient healthcare and sensor information system, Network and Computer Applications 34 (1) (2011) 402-417. 
The International Archives of the Photogrammetry, Remote Sensing and Spatial Information Sciences, Volume XL-1/W5, 2015 International Conference on Sensors \& Models in Remote Sensing \& Photogrammetry, 23-25 Nov 2015, Kish Island, Iran

S. Da`gtas, G. Pekhteryev, Z. Sahino`glu, H. C, am, N. Challa, Real-time and secure wireless health monitoring, International Journal of Telemedicine and Applications 2008 (2008) 1-10.

V. Oleshchuk, R. Fensli, Remote patient monitoring within a future $5 \mathrm{G}$ infrastructure, Wireless Personal

Communications 57 (2011) 431-439. 